\title{
FORMULATION ANDEVALUATION OF TRANSDERMAL DRUG DELIVERY OF TORASEMIDE
}

\author{
Sanjay Kumar Yadav*1, Ravikant Gupta2, SM Malipatil3, SK Gupta4 \\ IIMT College of Pharmacy, Greater Noida, Uttar Pradesh, India \\ Mylan Laboratories Ltd Indore, M.P. \\ HKES's College of Pharmacy, Gulbarga, Karnataka, India \\ Gurukul Kangri Viswavidyalaya, Haridwar, Uttaranchal \\ Email id: sanjay_yadav3333@yahoo.co.in
}

\begin{abstract}
A skin patch uses a special membrane to control the rate at which the liquid drug contained in the reservoir within the patch can pass through the skin and into the bloodstream. The basic components of any transdermal delivery system include the drug(s) dissolved or dispersed in a reservoir or inert polymer matrix; an outer backing film of paper, plastic, or foil; and a pressure-sensitive adhesive that anchors the patch to the skin. The adhesive is covered by a release liner, which needs to be peeled off before applying the patch to the skin. Drugs administered via skin patches include scopolamine, nicotine, estrogen, nitroglycerin, and lidocaine.
\end{abstract}

Non-medicated patch markets include thermal and cold patches, nutrient patches, skin care patches (a category that consists of two major sub-categories-therapeutic and cosmetic), aroma patches, weight loss patches and patches that measure sunlight exposure.

Keywords: Torasemide, sulphonyl urea, nitroglycerin, lidocaine.

\section{INTRODUCTION}

Controlled drug delivery Treatments of acute and chronic diseases have been accomplished by delivery of drugs to patients using various pharmaceutical dosage forms. This dosage form is known to provide a prompt release of drug. But recently several technical advancement has been done and resulted in new techniques from drug delivery. These techniques are capable of controlling the rate of drug release.

Transdermal drug delivery: The idea of delivering drugs through skin is old, as the use is reported back in 16th century B.C. The husk of castor oil plant in water was placed on an aching head.2 today the transdermal drug delivery is well accepted for delivering drug to systemic circulation.

Until recently, the use of transdermal patches for pharmaceuticals has been limited because only a few drugs have proven effective delivered through the skin typically cardiac drugs such as nitroglycerin and hormones such as estrogen.A skin patch uses a special membrane to control the rate at which the liquid drug contained in the reservoir within the patch can pass through the skin and into the bloodstream. The basic components of any transdermal delivery system include the drug(s) dissolved or dispersed in a reservoir or inert polymer matrix; an outer backing film of paper, plastic, or foil; and a pressure-sensitive adhesive that anchors the patch 
to the skin. The adhesive is covered by a release liner, which needs to be peeled off before applying the patch to the skin. Drugs administered via skin patches include scopolamine, nicotine, estrogen, nitroglycerin, and lidocaine.

Advantages of Transdermal Drug Delivery2, 3, 4, 5

Transdermal drug delivery gas many advantages over conventional drug delivery and can be discussed as follows.

$>$ They can avoid gastrointestinal drug absorption difficulties caused by gastrointestinal $\mathrm{pH}$, enzymatic activity, and drug interactions with food, drink, and other orally administered drugs.

They can substitute for oral administration of medication when that route is unsuitable, as with vomiting and diarrhea.

They avoid the first-pass effect, that is, the initial pass of drug substance through the systemic and portal circulation following gastrointestinal absorption, possibly avoiding the deactivation by digestive and liver enzymes.

$>$ They are noninvasive, avoiding the inconvenience of parenteral therapy.

$>$ They provide extended therapy with a single application, improving compliance over other dosage forms requiring more frequent dose administration.

Disadvantages of Transdermal Drug Delivery 3, 4, 6

>nly relatively potent drugs are suitable candidates for transdermal delivery because of the natural limits of drug entry imposed by the skin's impermeability.

$>$ Some patients develop contact dermatitis at the site of application from one or more of the system components, necessitating discontinuation.

$>$ The delivery system cannot be used for drugs requiring high blood levels.
The use of transdermal delivery may be uneconomic.

Structure of Skin.

$>$ Anatomy and physiology7, 8

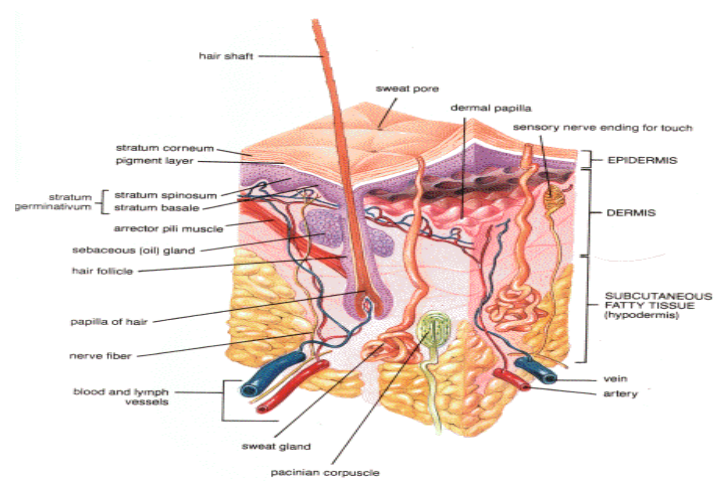

\section{Series of steps in sequence:}

1. Sorption of a penetrant molecule on surface layer of stratum corneum.

2. Diffusion through it and viable epidermis, and finally.

3. The molecule is taken up into the microcirculation for systemic distribution.

\section{Ideal properties of penetration enhances $^{11}$}

Material should be pharmacologically inert.

$>$ It should be non-toxic, non-irritant, non allergenic.

$>$ The action should be immediate and the effect should be suitable and predictable.

Upon removal of the material, skin should be immediately and completely recover its normal barrier properties.

The enhancer should not cause loss of body fluids, electrolytes or other endogenous materials.

\section{Iontophoresis and Sonophoresis ${ }^{12}$}

In addition to chemical means, some physical methods are being used to 
enhance transdermal drug delivery and penetration, as, iontophoresis and sonophoresis.

\section{Iontophoresis}

Iontophoresis is delivery of charged chemical compound across the skin membrane using electrical field. However, iontophoresis-enhanced transdermal drug delivery has shown some promise as a mean of peptide and protein administration.

\section{Electroporation}

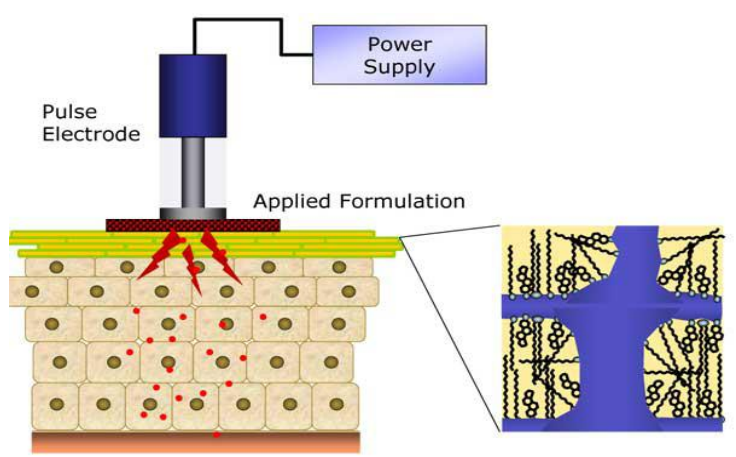

\section{Microreservoir dissolution-controlled TDD systems:}

A hybrid of reservoir- and matrix dispersion-type drug delivery systems, which contains dug reservoir formed by first suspending the drug solids in an aqueous solution of water-miscible drug solubilizer e.g. propylene glycol, then homogeneously dispersing the drug suspension, to form thousands of unleachable microscopic drug reservoirs with controlled aqueous solubility, in a lipophilic polymer, by high shear mechanical force.

\section{General clinical considerations in the use of TDDSs3}

The patient should be advised of the following general guidelines. The patient should be advised of the importance of using the recommended site and rotating locations within the site. Rotating locations is important to allow the skin to regain its normal permeability and to prevent skin irritation.

1. TDDSs should be applied to clean, dry skin relatively free of hair and not oily, inflamed, irritated, broken, or callused. Wet or moist skin can accelerate drug permeation beyond time. Oily skin can impair the adhesion of patch. If hair is present at the site, it should be carefully cut, not wet shaved, nor should a depilatory agent be used, since later can remove stratum corneum and affect the rate and extent of drug permeation.

2. Use of skin lotion should be avoided at the application site, because lotions affect the hydration of skin and can alter partition coefficient of drug.

3. Cutting should not physically alter TDDSs, since this destroys integrity of the system.

4. The protecting backing should be removed with care not to touch fingertips. The TDDS should be pressed firmly against skin site with the heel of hand for about 10 seconds.

\section{LITERATURE SURVEY}

The role of hair follicles in transdermal delivery remains difficult to elucidate due partly to animal model complications. According to reports ${ }^{16,17,37}$ hairy skin sites and different follicle densities can influence the penetration process.

Frum Y., et al., ${ }^{35}$ Studied the influence of drug partition coefficient on follicular penetration in Invitro human skin studies seven steroids of different partition coefficient were taken and studied Ko/w via transport these skin preparation by heat technique (Kligman and Christophers) ${ }^{36}$ While Stratum corneum (SC) membranes were prepared using a protocol that was very similar to but not identical to the methodology developed by Essa et al. (2002). ${ }^{37}$ 
Rama Rao P., et al., ${ }^{38}$ evaluated the Comparative in vivo studies of propranolol hydrochloride after oral and transdermal administration in rabbits. Transdermal patch of The polymeric films composed of ethyl cellulose:PVP: drug (9:1:3, $8: 2: 2$ and $8: 2: 3$ ) were prepared by mercury substrate method. ${ }^{89}$

Sintov A.C., et al., ${ }^{39}$ investigated Transdermal drug delivery using micro emulsion and aqueous systems. Due to their unique physicochemical properties, micro emulsions offer advantages over traditional topical and transdermal drug delivery formulations. The permeability of diclofenac through animal skin was determined in vitro with a Franz diffusion cell system.

Manosroi .A., et al., ${ }^{40}$ studied stability and transdermal absorption of topical amphotericin B liposome formulations. Liposomes are widely used as carriers for a variety of drugs, including their application to topical delivery the development of liposomes aims to improve the delivery of applied drugs through the skin.

Garcia M.T.J et al., ${ }^{44}$ evaluated transdermal delivery of Ketoprofen (KP) by the influence of drug-dioleylphosphatidylcholine

(DOPC)

interactions phospholipids have received attention as penetration enhancers.

Batchelder R.J., et al., ${ }^{45}$ accessed the in vitro transdermal delivery of the major catechins and caffeine from extract of Camellia sinensis.

Sriamornsak P., et al., ${ }^{52}$ prepared a novel gel formation method, by allowing calcium ions to diffuse from source to form gel films with pectin or alginate. Polysaccharide solutions (2\% w/w) were prepared in deionized water.

Johannes P. Venter J.P., et al., ${ }^{53}$ performed a comparative study of an in situ adapted diffusion cell and an in vitro Franz diffusion cell method for transdermal absorption of doxylamine. A cut was made in the dorsal skin of the anaesthetized mouse, without damaging or stretching the skin.
Fulzele S.V., et al., ${ }^{55}$ investigated polymerized rosin novel film forming polymer for drug delivery. Rosin and rosin derivatives are polymeric biomaterials and have been pharmaceutically evaluated as microencapsulating materials (Pathak et al., Sheorey and Dorle, ${ }^{56}$ and as anhydrous binding agents in tablets (Pathak and Dorle, Ramani et al.,). ${ }^{56}$

Satturwar P.M et al., ${ }^{58}$ synthesized and evaluate new rosin derivatives for pharmaceutical coating. The use of natural polymers and their semisynthetic derivatives in drug delivery continues to be an area of active research despite the advent of synthetic polymers.

Satturwar P.M. et al., ${ }^{59}$ studied evaluation of polymerized rosin for the formulation and development of transdermal drug delivery system. Rosin is a solid resinous mass obtained naturally from pine trees.

Murthy N.S., et al., ${ }^{60}$ formulation and evaluation of controlled release transdermal patches of theophylline - salbutamol sulphate the high dose of theophylline $150 \mathrm{mg}$ in patch was achieved by absorption of theophylline on the polymer in pressure of electrolyte $0.1 \% \mathrm{w} / \mathrm{v}$ sodium chloride.

Williams A.C. et al., ${ }^{68,69}$ reviewed Penetration enhancers and suggest Human skin is a remarkably efficient barrier, designed to keep our insides in and the outsides out. One long-standing approach to increase the range of drugs that can be effectively delivered via this route has been to use penetration enhancers, chemicals that interact with skin constituents to promote drug flux.

Lee P.J. et al., ${ }^{76}$ investigated the effect of various chemical enhancers in the transdermal delivery of lidocaine. One class of chemical enhancers studied was LDA.

Yamamoto A. et al., ${ }^{78}$ synthesized three novel lipophilic derivatives of Phe-Gly to improve the transdermal absorption of this model dipeptide. three novel lipophilic derivatives of phenylalanylglycine (Phe-Gly), C4-Phe-Gly, C6-Phe-Gly and 
C8-Phe-Gly by chemical modification with butyric acid (C4), caproic acid (C6) and octanoic acid (C8).

Babu R.J., et ${ }^{78}$ evaluated effect of penetration enhancers on the release and skin permeation of bupranolol from reservoir-type transdermal delivery systems.

Shina S.C., et al., ${ }^{80}$ developed tretinoin gels for enhanced transdermal delivery. To improve the permeability of drugs, the use of penetration enhancers is a logical approach to increase the drug flux across the epithelium.

Qvist M.H., et al., ${ }^{83}$ studied Release of chemical permeation enhancers from drug-in-adhesive transdermal patches.

Muriel C., et.al. ${ }^{84}$ investigates effectiveness and tolerability of the buprenorphine transdermal system in patients with moderate to severe chronic pain. Buprenorphine's high analgesic potency, high lipophilicity, and low molecular weight make it ideal for delivery in a transdermal formulation.

Maillard-Salin D.G., et al., ${ }^{87}$ evaluated the effect of adhesive on TDDS Adhesion onto the skin with silicone was estimated by the $90^{\circ}$ peel test using a traction machine (Zwick). Samples (10 mm wide by $45 \mathrm{~mm}$ long) of placebo patch were stuck on the right forearm of healthy volunteers.

\section{PLAN OF WORK:}

$>$ Selection of Drug and Excipients

$>$ Preformulation Study

A concise stepwise account of the various tasks that need to be executed for successful accomplishment of the research envisaged.

Analytical method selection:

\section{$>$ UV-VIS spectrophotometry}

$>$ FTIR

UV-VIS spectrophotometry is suitable for initial screening studies as the method is convenient and less time consuming. Both qualitative and quantitative estimations can be performed.
FTIR is a good method for estimating drug excipient interactions. Qualitative estimations can be very well carried out.

Evaluation of film:

The prepared medicated films was evaluated for
$>$ Thickness
$>$ Weight variation
$>$ Percent flatness
$>$ Moisture content
$>$ Moisture uptake
$>$ Tensile strength
$>$ Modulus of elasticity
$>$ Percent elongation
$>$ Drug content
$>$ Area variation

\section{Thickness ${ }^{111}$}

The thickness of films was measured by digital Vernier caliper with least count $0.001 \mathrm{~mm}$. The thickness uniformity was measured at five different sites and average of five readings was taken with standard deviation.

\section{Weight variation test ${ }^{112}$}

Weight variation test was done by weighing each of five films individually. The average of film was taken as weight of films. The three disks of 3.14 $\mathrm{cm}^{2}$ was cut and weighed on electronic balance for weight variation test. The test was done to check the uniformity of weight and thus check the batch-to-batch variation.

\section{Percent flatness $^{112}$}

The percent flatness was measured by cutting the film into three strips from canter of the film. The strips were cut so that each should have $4 \mathrm{~cm}$ length and $0.5 \mathrm{~cm}$ breadth. Each strip was put on the clean surface without applying any additional pressure and measured its length to nearest centimeter by digital Vernier caliper. The percent flatness was calculated by the following formula. 


$$
\text { Percent flatness }=\frac{(100 \mathrm{~L} 1+100 \mathrm{~L} 2+100 \mathrm{~L} 3) / 3}{100}
$$

\section{Moisture content ${ }^{114}$}

The film was weighed and kept in a desiccator containing calcium chloride at $40^{\circ} \mathrm{C}$ in a drier for at least $24 \mathrm{hr}$ or more until it showed a constant weight and was reported in terms of percentage (by weight) moisture content.

\section{Moisture uptake ${ }^{114}$}

The films casted in plastic moulds were used for moisture uptake studies. A weighed film kept in glass chamber at $40^{\circ} \mathrm{c}$ For $24 \mathrm{~h}$ was taken out and exposed to two different relative humidity of $75 \%$ (saturated solution of sodium chloride) and 93\% (saturated solution of ammonium hydrogen phosphate) in two different glass chamber, repectively, at room temperature. Then the weights were measured periodically.

\section{Final weight - initial weight

Percent moisture uptake $=\quad \times 100$

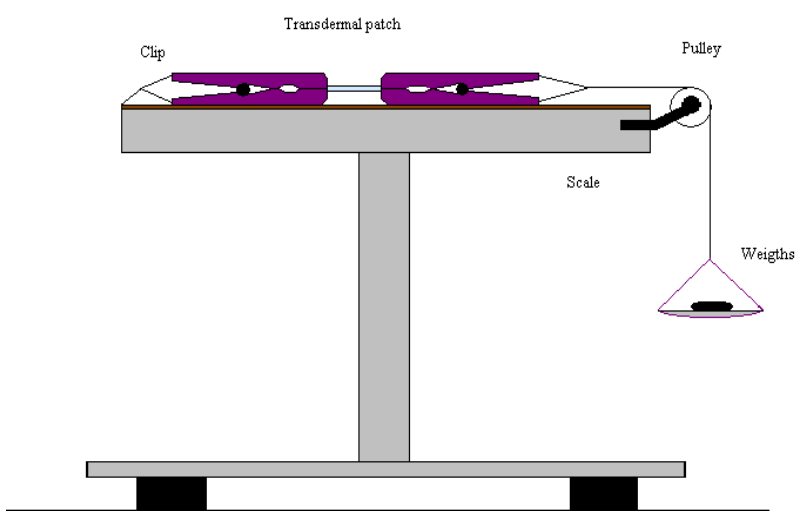

\section{Percent elongation ${ }^{113}$}

The percent elongation at break was measured by formula given below.

$$
\text { Total elongation } \quad \mathbf{L}-\mathbf{L}_{\mathbf{0}}
$$

$$
\text { Strain }(E)=\frac{}{\text { Original length }} \times 100=\frac{}{L_{0}} \times 100
$$

Where, $\mathrm{L}=$ length after force was applied

$$
L_{0}=\text { original length }
$$

\section{Drug content}


The patch of area $3.14 \mathrm{~cm}^{2}$ was cut and dissolved in methanol and the remaining volume was made up with methanol to $100 \mathrm{ml}$ in $100 \mathrm{ml}$ volumetric flask. Then $1 \mathrm{ml}$ was withdrawn from the solution and diluted to $10 \mathrm{ml}$. The absorbance of the solution was taken at $288 \mathrm{~nm}$ and concentration was calculated. By correcting dilution factor, the drug content was calculated.

\section{Area variation ${ }^{114}$}

The films were cut by using cutter. The change in area would change the drug content of the patch. The error in cutting was checked by measuring the area of the films. Three disks, same disks used for weight variation tests, were taken for accurate measurement of area of films. Taking accurate dimensions of films using Vernier caliper did the measurement of area. The calculated area was compared with the actual area.

\section{Results and Discussion:}

\section{Determination of $\lambda$ max}

The spectrum obtained is shown in Fig 21. The wavelength of maximum absorbance ( $\lambda$ max.) was found to be $288 \mathrm{~nm}$ in methanol. The peaks shown in fig. 21 are very much similar to the standard

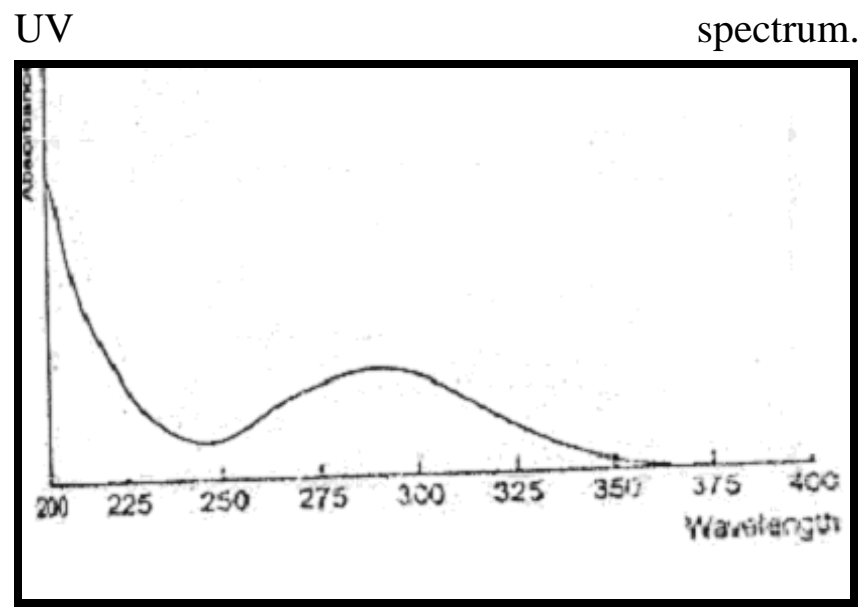

גmax of torasemide in methanol

\section{Calibration curve of Torasemide}

\section{For Methanol}

The absorbance values were obtained as shown in Table no.11. Using absorbance-concentration data; a Lambert and Beer's graph was plotted.
Data of concentrations and absorbance

\begin{tabular}{||c|c||}
\hline Concentration (mcg/ml) & Absorbance \\
\hline 2 & 0.072 \\
\hline 4 & 0.130 \\
\hline 6 & 0.196 \\
\hline 8 & 0.214 \\
\hline 10 & 0.237 \\
\hline 12 & 0.300 \\
\hline 14 & 0.325 \\
\hline 16 & 0.369 \\
\hline 18 & 0.401 \\
\hline 20 & 0.451 \\
\hline
\end{tabular}

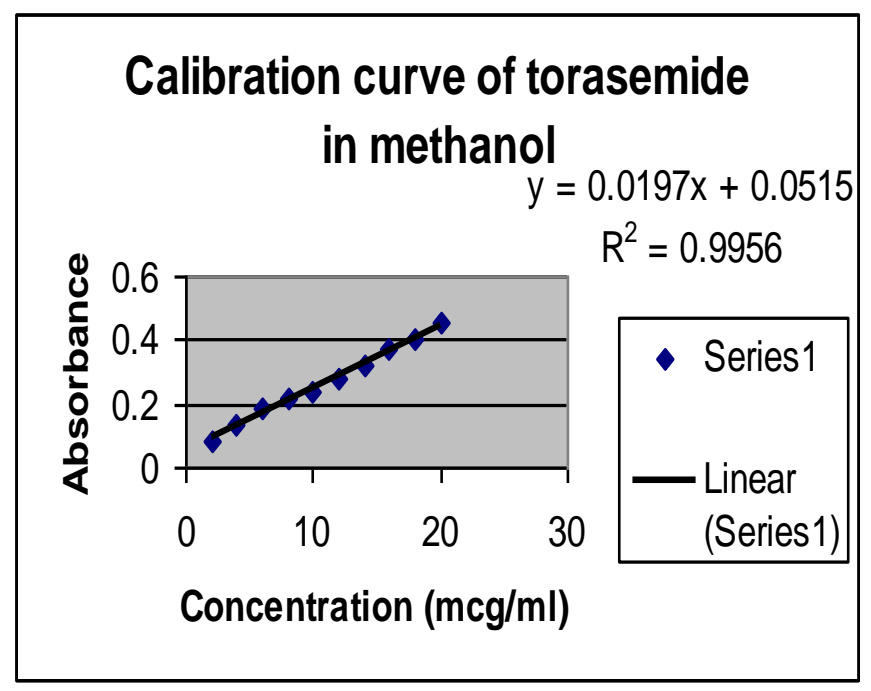

Calibration curve of Torasemide in methanol

\section{SUMMARY \& CONCLUSION}

An ideal dosage regimen in the drug therapy of any disease is one, which immediately attains the desired therapeutic concentration of drug in plasma (or at the site of action) and maintains it constant for the entire duration of treatment. This is possible through administration of conventional dosage form in a particular dose and at a particular frequency. But as reported in literature conventional drug delivery has its own limitations, which switch over the formulator to developed new formulation. This overcomes the number of drawbacks associated with conventional dosage drug delivery system. The past decade has seen 
major advances in developing a drug through concept and technique of controlled and targeted drug delivery system. ${ }^{127}$

Therefore an ideal controlled drug delivery system is the one, which delivers the drug at a predominant rate, locally or systematically, for a specific period of time. Despite of number of approaches to deliver a drug in systemic circulation at predetermined rate and maintain clinically effective concentration over prolong period of time.

In the present study, it was intended that the side effects of the oral administration of torasemide be overcome by delivering torasemide transdermally. In this study, it was desired to design a TDDS of torasemide using polymeric matrix film. This allows one to control the overall release of drug via an appropriate choice of polymers.

Methanol was incorporated in the transdermal system because it significantly enhanced the permeation rate of torasemide in an earlier study.

Drug -carrier interaction-Drug interaction study for Torasemide and exicipients that no interaction between them. That indicates that drug can be safely incorporated into matrix system, for formulation of transdermal therapeutic system.

Film thickness and appearance- The film formed is transparent and uniform. The film shows increase in thickness was linear with in polymer concentration.

Weight variation -The results of weight variation of films were satisfactory and uniform

Moisture content, Moisture uptake- The moisture content in the formulations was found to increase with the increasing the conc. of drug and hydrophilic polymer HEC.The water absorption capacity was found to increase with increase in conc. of hydrophilic polymer HEC with increase RH.

\section{REFERENCES:}

1. Chein Y.W. Sustained and controlled release drug delivery systems, In:J.R.Robinson 2nd ed., New York, Marcel Dekker, Inc.; 1978, pp 223-227.

2. Mishra A.N., Transdermal Drug Delivery, In: Jain N.K., , Controlled and N Chien Y.W. "Novel Drug Delivery Systems", 2nd ed,.New York ,Marcel Dekker, Inc., 1987,pp-211-217.

3. Finnin B C, Morgan T M, Transdermal penetration,Int J Pharm Sci ,1999; 88:pp 955- 958.

4. Allen L V, Popovich N G, Ansel H C, Ansel's Pharmaceutical Dosage Forms and Drug Delivery Systems, 8th ed, Lippincott Williams \& wilkins, 2005;pp 298-315.

5. Barry B, Transdermal Drug Delivery, In: Aulton M E, Pharmaceutics: The Science of Dosage Form Design, Churchill Livingston, 11(2), 2002, pp 499-533.

6. Cleary G W, Transdermal controlled release systems, First Edition, Medical Applications of Controlled Release, Vol I, pp 203-251.

7. Vyas S P, Khar R K, Controlled Drug Delivery:Concepts and Advances, Vallabh Prakashan, 1st ed, 2002, pp 411-447.

8. Wilson K. J. W., Waugh A., In:Ross and Wilson: Anatomy and Physiology In Health and Illness", 8th ed, Churchill Livingstone, 1996, pp 360-366.

9. Barry B.W.; "Dermatological Formulations: Percutaneous Absorption", DRUGS AND PHARMACEUTICAL SCIENCES, Vol - 18, Marcel Dekker, Inc., 1983, pp1-39. 
10. Stanley Scheindlin, Transdermal Drug Delivery: Past, Present, Future, Molecular Interventions, 2004; 4(6), pp 308-312.

11. Swarbrick J.and Boylan, J.C., Eds.Encyclopedia of Pharmaceutical Technology, 2 nd Ed. New York: Marcel Dekker, Inc.; 2002, pp 1573-1587.

12. Sharma A; Kara M, Smith F.R., Krishnan T.R., "Transdermal drug delivery using electroporation I. Factors influencing in vitro delivery of Tetrazosin HCL in hairless rats". J.Pharm.Sci. 89(2), 2000; pp 528-523.

13. United States Patent: 6,673,363 Issued: January 6, 2004 Title: Transdermal and topical administration of local anesthetic agents using basic enhancers Inventors: Luo; Eric C. (Plano, TX); Gricenko; Nicole T. (San Diego, CA); Hsu; TsungMin (San Diego, CA).

14. Funke AP, Gunther C, Muller RH, Lipp R., "In-vitro release and transdermal fluxes of a highly lipophilic drug and of enhancers from matrix TDS". J Control Rel, 2002; 18; 82(1), pp 63-70.

15. Akimoto T, Nagase Y, "Novel transdermal drug penetration enhancer: synthesis and enhancing effect of alkyldisiloxane compounds containing glucopyranosyl group", J Control Rel., 88(2), 2003; pp 243-252.

16. Hirvonen J, Murtomaki L, Kontturi K, "Effect of diffusion potential, osmosis and ion-exchange on transdermal drug delivery theory and experiments", Journal of Control Release, 56(3), 1998; pp 33-39.

17. Fang JY, Lin HH, Chen HI, Tsai YH, "Development and evaluation on transdermal delivery of Enoxacin via chemical enhancers and physical iontophoresis", Journal of Control Rel, 54(3), 1998; pp 293-304.
18. Oh SY, Jeong SY, Park TG, Lee JH, "Enhanced transdermal delivery of AZT (Zidovudine) using iontophoresis and penetration enhancer", Journal of Control Rel, 51(2), 1998; pp161-168.

19. Fang JY, Sung KC, Lin HH, Fang CL, "Transdermal iontophoretic delivery of enoxacin from various liposomeencapsulated formulations" J. of Control Rel., 60(1), 1999; pp 1-10.

20. Pillai O, Panchagnula R., "Transdermal iontophoresis of insulin. V. Effect of terpenes", J Control Release, 88(2), 2003; pp 287-296.

21. Vanbever R, Langers G, Montmayeur S, Preat V, "Transdermal delivery of Fentanyl: rapid onset of analgesia using skin electroporation" J. of Control Rel., 50(3), 1998; pp 225-235.

22. Denet AR, Preat V. "Transdermal delivery of timolol by electroporation through human skin", J. of Control Rel., 88(2), 2003; pp 253-262.

23. Bose S, Ravis WR, Lin YJ, Zhang L, Hofmann GA, Banga AK, "Electrically assisted transdermal delivery of buprenorphine", Journal of Control Release,73(2), 2001; pp 197-203. 24. Panchagnula R., "Transdermal delivery of drugs", Indian J Pharmacol, 29(2), 1997; pp 140-156.

24. N.A.Kshirsagar, "Drug Delivery Systems", Indian Journal of Pharmacology, 32(3), 2000; pp 54-61.

25. Murthy S N, Hamsa V, Bhaskaran S, "Comparative release studies of transdermal films of Terbutaline sulphate across various diffusion layers", Indian J Pharm Sci, 58(4), 2001;pp 150-151.

26. Murthy S N, Shoba Rani, Hiremath R, "Physical and chemical permeation 
enhancers in transdermal delivery of Terbutaline sulphate", AAPS PharmaSciTech, 2(1), 2001; pp1-5.

27. Manvi FV, Dandagi PM, Gadad AP, Mastiholimath VS, Jagadeesh T, "Formulation of a transdermal drug delivery system of ketotifen fumarate" Indian J Pharm Sci, 65 (3), 2003; pp 239243.
28. Kusum D.V, Saisivam S, Maria G. R., "Deepti P. U. Design and Evaluation of Matrix Diffusion Controlled Transdermal Patches of Verapamil Hydrochloride", Drug Development and Industrial Pharmacy, 2

29. 9(5), 2003, pp $495-503$. 